\title{
Parvovirus as a cause of hydrops fetalis: detection by in situ DNA hybridisation
}

\author{
H J PORTER, T Y KHONG, M F EVANS, V T-W CHAN, K A FLEMING \\ From the Nuffield Department of Pathology, University of Oxford, John Radcliffe Hospital, Oxford
}

SUMMARY Lung tissue from 13 cases of unexplained non-immunological hydrops fetalis was examined by in situ hybridisation to detect parvovirus. Four specimens contained parvovirus DNA in cells in the blood vessel lumina and alveoli. Twenty six control cases were negative for parvovirus DNA. As there was no known epidemic of parvovirus infection during the study period, this suggests that parvovirus is a relatively common cause of non-immunological hydrops fetalis. In situ hybridisation may have a role in clinical medicine, particularly for retrospective investigations.

The underlying causes of non-immunological hydrops fetalis are varied, and often no aetiological factor can be found to explain the hydropic state. ${ }^{1}$ A previous publication described 50 cases of non-immunological hydrops fetalis examined at the John Radcliffe Maternity Hospital between 1974 and 1983.' The most common underlying causes for the hydrops were cardiovascular anomalies and chromosomal abnormalities, but 13 cases remained either unexplained or were thought to be associated with unidentified viral infection. Unfortunately, the precise organisms could not be identified due to technical problems in the investigation of necropsy material. In situ DNA hybridisation can overcome most of these problems and, furthermore, can allow specific viral DNA to be localised in fixed paraffin embedded tissue. ${ }^{2}$ Recent reports showing that parvovirus infection during pregnancy is associated with intrauterine death and hydrops fetalis ${ }^{34}$ prompted us to re-evaluate our cases of unexplained non-immunological hydrops fetalis using in situ hybridisation to detect parvovirus.

\section{Material and methods}

Paraffin embedded blocks of lung tissue from three groups were examined. Group 1 comprised the 13 cases mentioned above (eight intrauterine deaths with gestational ages of 24 to 39 weeks, of which four were macerated, and five neonatal deaths with gestational ages of 27 to 33 weeks and survivals from a few minutes to 15 hours). The second and third groups were matched for gestational age and for intrauterine or neonatal death. The second group consisted of 13 cases that had hydrops fetalis of known cause, and the

Accepted for publication 16 December 1987 third group comprised 13 cases which were nonhydropic and had died from other causes.

Lung tissue from a hydropic fetus shown to be infected by parvovirus by dot hybridisation studies ${ }^{3}$ and from a hydrops fetus with Turner's syndrome confirmed by chromosome analysis, were used as known positive and negative controls, respectively.

\section{IN SITU HYBRIDISATION}

Sections of routine paraffin embedded lung tissue were cut on to slides coated with $2 \%$ aminopropyltriethoxysilane in acetone ${ }^{2}$ and baked overnight at $80^{\circ} \mathrm{C}$. The slides were dewaxed in three changes of xylene, washed in three changes of industrial spirit, and air dried. DNA was unmasked by exposing the sections to $0.1 \%$ pepsin $(\mathrm{w} / \mathrm{v})$ in $200 \mathrm{mM}$ hydrochloric acid at $37^{\circ} \mathrm{C}$ for 15 minutes. Sections were washed in several changes of distilled water and allowed to air dry. Hybridisation mix $(10 \mu l)$ with biotinylated probe at a final concentration of $500 \mathrm{ng} / \mathrm{ml}$ was added to each section and a coverslip applied.

The final concentration of the components of the hybridisation mix were $10 \%(\mathrm{w} / \mathrm{v})$ dextran sulphate, $50 \%(\mathrm{v} / \mathrm{v})$ formamide, phosphate buffered saline (PBS) (24 mM Na $\mathrm{HPO}_{4}, 80 \mathrm{mM} \mathrm{KH} \mathrm{PO}_{4}, 300 \mathrm{mM}$ $\mathrm{NaCl}(\mathrm{pH} \mathrm{7 \cdot 2),2} \mathrm{mM} \mathrm{edetic} \mathrm{acid} \mathrm{(pH} \mathrm{7.0),} 250 \mu \mathrm{g} / \mathrm{ml}$ (w/v) sonicated herring sperm DNA (Sigma), and $1 \mathrm{mg} / \mathrm{ml}(\mathrm{w} / \mathrm{v})$ sonicated human placental DNA. For each case there was one slide with three sections on it. To one section biotinylated B19 parvovirus riboprobe pYT 104 (Peter Tattershall) was added, to another, biotinylated cytomegalovirus (Enzo Biochem Inc, USA) and to the third, biotinylated plasmid vector pBR322.

The sections and probe were simultaneously denatured for 10 minutes at $90^{\circ} \mathrm{C}$ and then hybridised for 
90-150 minutes at $37^{\circ} \mathrm{C}$. The coverslips were carefully washed off using PBS and the slides were washed in $0.5 \%$ Triton $\times 100$ in PBS. Non-specific protein binding sites were blocked using $5 \%$ bovine serum albumin (BSA) in $0.5 \%$ Triton/PBS for 20 minutes at $37^{\circ} \mathrm{C}$. After a further rinse in PBS the slides were incubated with avidin-alkaline-phosphatase conjugate (Dakopatts A/S, Denmark) at a concentration of 1 in 250 (protein concentration $2.8 \mathrm{mg} / \mathrm{ml}$ ) in PBS $/ 0.5 \%$ triton/ $5 \%$ BSA at $37^{\circ} \mathrm{C}$ for $30-45$ minutes. The slides were washed in several changes of PBS $/ 0.5 \%$ triton, then PBS, and finally alkaline phosphatase incubation buffer (AP9-6). The slides were developed in nitroblue tetrazolium and bromo-4-chloro-3-indolyl phosphate in AP9.6 as described previously. ${ }^{2}$ A positive reaction was shown as a purplish brown precipitation at the site of hybridisation. DNAse digestion was carried out as described. ${ }^{2}$ A section from each case was stained with haematoxylin and eosin.

\section{Results}

The in situ hybridisation technique yielded consistently reproducible results with hybridisation of the parvovirus probe to tissue from the hydrops case of confirmed parvovirus infection but not to the hydropic Turner's tissue section.

Four of the 13 cases in group 1 were positive with the parvovirus probe (fig 1). All of these four were intrauterine deaths, two of which were macerated. This signal was sensitive to DNAse. None of these cases was positive with the CMV or pBR322 probes. All 26 cases in groups 2 and 3 were negative with all probes. The positive cells were distributed both within the lumina of blood vessels and alveolar spaces. Most of these appeared to be red blood cells.

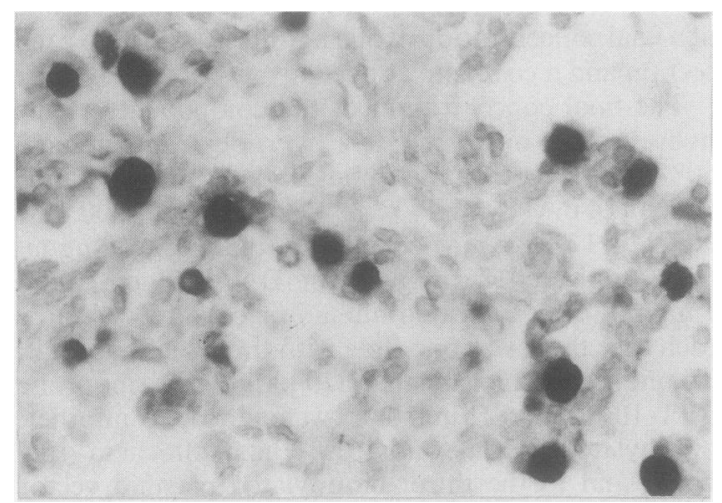

Fig 1 In situ hybridisation of lung with biotinylated parvovirus probe. Numerous positive cells can be seen within blood vessel lumina and alveoli.

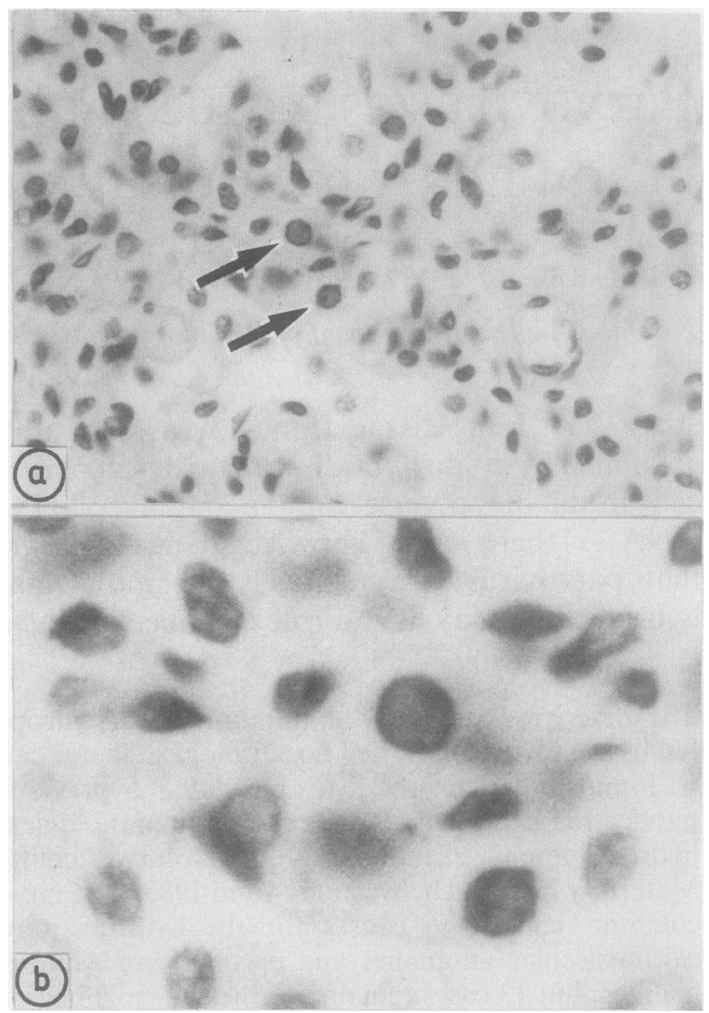

Fig 2 (a) Lung showing parvovirus inclusions (arrows) (haematoxylin and eosin); (b) higher magnification of cells arrowed in $(a)$.

On staining with haematoxylin and eosin (figs $2 a-b$ ) pink/purple intranuclear inclusions were seen in the four cases positive by in situ hybridisation. All these inclusions contained parvovirus DNA. Many more cells, however, which did not contain recognisable intranuclear inclusions on haematoxylin and eosin staining, were also positive by in situ hybridisation. Conversely, no cases were positive in the absence of intranuclear inclusions.

\section{Discussion}

Parvovirus infection is usually a mild childhood illness, fifth disease, in which there is an erythematous rash but no other symptoms. In pregnant women the virus may cross the placenta but the incidence of transplacental transmission in pregnant women with parvovirus infection is unknown and the prognosis and long term outcome for fetuses with intrauterine infections is uncertain. ${ }^{5}$ Parvovirus however, is a known cause of hydrops fetalis, intrauterine death, ${ }^{34}$ and spontaneous abortion, ${ }^{6}$ although it is not a 
common cause of congenital abnormalities or neonatal disease. ${ }^{67}$

Three points are worthy of note from this study. Firstly, four of the 13 cases of unexplained hydrops fetalis contained parvovirus DNA in lung tissues. This suggests that the infection may be more common than is generally thought, particularly as our cases did not occur during an epidemic. We estimate that this method of in situ hybridisation is capable of detecting 10 copies of human papilloma virus genome in each cell, ${ }^{2}$ which if extrapolated to B19 parvovirus, would imply detection of a similar number of viral genome copies (B19 parvovirus riboprobe contains 8.3 pairs of parvovirus genome). Thus if B19 parvovirus was present in lower copy numbers in some of our cases, the observed $30 \%$ prevalence rate could be an underestimate. Whether these findings will be generally applicable in wider populations requires further study.

Secondly, as we did not detect parvovirus in any of the cases of non-hydropic, unexplained intrauterine deaths, it would seem that intrauterine death in parvovirus infection results from hydrops fetalis, presumably consequent on haemolysis and anaemia. Conversely, in the absence of hydrops fetalis, parvovirus infection does not seem to be a common cause of intrauterine death. Thirdly, our findings support the view that parvovirus infection is not a common cause of congenital abnormalities, as in all our cases the fetuses were anatomically normal.

This paper also illustrates the potential clinical importance of in situ hybridisation, particularly for retrospective studies. Thus although inclusions can be seen on routine haematoxylin and eosin staining ${ }^{48}$ this study illustrates that in situ hybridisation identifies conclusively the inclusions as parvovirus. In situ hybridisation also shows more virus particles than are apparent on haematoxylin and eosin staining. Furthermore, while the diagnosis of parvovirus infection can be made serologically ${ }^{6}$ for retrospective analysis this requires stored serum which may not be available unlike archival histopathological material.
Similarly, while dot hybridisation on DNA extracted from fresh or fixed tissues can identify specific viral sequences, ${ }^{3}$ it does not provide information on the cytological distribution of the virus. In contrast, this type of information is provided by in situ hybridisation and, therefore, further studies to identify the tissue distribution and precise cell type in parvovirus infection are underway. The method is, of course, applicable to other viruses.

We thank Dr J W Keeling, department of paediatric pathology, John Radcliffe Maternity Hospital, Oxford, and Dr E S Gray, department of pathology, University Medical Buildings, Foresterhill, Aberdeen, for the tissue used in this study. We are grateful to Professor P Tattershall, departments of laboratory medicine and human genetics, Yale University, USA, for the parvovirus probe. Miss Lesley Watts typed the manuscript.

HJP is a British Heart Foundation Junior Research Fellow. This research was funded in part by Oxford District Health Authority.

\section{References}

1 Keeling JW, Gough DJ, Iliff P. The pathology of non-rhesus hydrops. Diagn Histopathol 1983;6:89-111.

2 Burns J, Graham AK, Frank C, Fleming KA, Evans MF, McGee JO'D. Detection of low copy human papilloma virus DNA and mRNA in routine paraffin sections of cervix by non isotopic in situ hybridisation. J Clin Pathol 1987;40:858-64.

3 Brown T, Anand A, Ritchie LD, Clewley JP, Reid TMS. Intrauterine parvovirus infection associated with hydrops fetalis. Lancet 1984;ii:1033-4.

4 Anand A, Gray ES, Brown T, Clewley JP, Cohen BJ. Human parvovirus infection in pregnancy and hydrops fetalis. $N$ Engl $J$ Med 1987;316:183-6.

5 Hall $\mathrm{S}$. Infection with parvovirus during pregnancy. $\mathrm{Br}$ Med $\mathrm{J}$ 1985;290:713-4.

6 Mortimer PP, Cohen BJ, Buckley MM, et al. Human parvovirus and the fetus. Lancet 1985;ii: 1012.

7 Gray ES, Anand A, Brown T. Parvovirus infections in pregnancy. Lancet 1986;:208.

8 Burton PA. Intranuclear inclusions in marrow of hydropic fetus due to parvovirus infection. Lancet 1986;ii:1155. 